\title{
THE ASSESSMENT STRATEGY: AN ELUSIVE CURRICULUM STRUCTURE
}

\section{Scholtz}

Fundani CHED

Cape Peninsula University of Technology

Bellville, Cape Town

e-mail: scholtzd@cput.ac.za

\section{ABSTRACT}

The unprecedented scale of curriculum development in response to national imperatives has prompted questions on curriculum approaches and strategies. The focus of this article is on how four departments conceived assessment during the recurriculation of diploma qualifications. The findings suggest that assessment is approached from a technicist perspective and compliance with principles of good assessment practice. In response to the findings, the purpose and structure of an assessment strategy as an over-arching mechanism to inform and guide assessment practices at programme level are explored. It is argued that a collaborative, programme-specific assessment strategy creates an opportunity for synergy to achieve the purpose of the qualification and for holistic graduate development.

Keywords: assessment strategy, higher education, curriculum revision, collaboration

It is widely acknowledged that the curriculum and knowledge in higher education are especially visible through (and often constructed by) assessment practices. If this is the case, it matters greatly what perspectives and theoretical tools are brought to bear on the task of understanding these practices (James 2014, 155).

\section{INTRODUCTION}

Higher education in South Africa is in the process of unprecedented curriculum revision and curriculum development owing to the Council on Higher Education's (CHE) revised Higher Education Qualifications Sub-Framework (HEQSF) (CHE 2013). This is particularly pertinent for universities of technology (UoTs), where certain qualifications will be phased out in favour of new qualifications that now feature on the HEQSF (CHE 2013). The first phase of curriculum renewal commenced with the revision of diploma qualifications where up to 50 per cent changes could be effected to existing qualifications. The construct of 'curriculum' at this institution was viewed within the broader all-encompassing definition where 'curriculum is more than just content ... but can be defined as a set of purposeful, intended experiences ... which may be divided into four parts: content [programme development], organisation [programme design], 
learning and teaching methods and assessment' (Knight 2001, 369). Curriculum revision for the diploma programmes was a process of intensive critical reflection of content, approaches, methods, activities, procedures and practices for teaching, learning and assessment. The dynamic, organic nature of curriculum revision and curriculum development refutes the reductionist view that curriculum is a static blueprint for implementation. This institution viewed the revision of diplomas as a window of opportunity to bring about the kinds of changes that would render the qualifications current, responsive to industry and society, and relevant regarding knowledge, skills and values for a super-complex world (Barnett 2000). This article focuses on how four departments conceived assessments for their diploma programmes. The discussion is located within the framework of different perspectives of assessment as espoused by James (2014). The purpose of this article is to foreground the importance of thinking strategically about assessment at programme level. Within the context of this article, a programme refers to 'a purposeful structured set of learning experiences that leads to a qualification' (CHE 2013, 44), and consists of a composite, complementary subject structure across the levels of learning. This notion of a programme-wide systems approach to assessment is reinforced by Knight (2000, 239), who argues 'that attention should be paid to the collection of courses or modules that together comprise a programme leading towards a named award'. He claims that assessment strategies 'only make operational sense if attention is concentrated upon assessment arrangements in complete programmes' of study (Knight 2000, 239). Although this article raises issues of assessment, it is not viewed in isolation of teaching and learning. Given the institutional stance of constructive alignment as an approach to teaching and learning, assessment is viewed as a constituent part of a whole within a holistic framework of teaching and learning practice.

This article provides brief insight into the purpose and nature of curriculum revision, followed by theoretical perspectives on assessment and its relation to teaching and learning. Responses provided by four departments were evaluated and discussed in relation to how each department conceived assessment for their diplomas respectively. Considerations for developing an assessment strategy for a programme of study are presented to define how assessment could best serve the purpose of developing graduates from a collaborative, complementary, constituent staff position.

While the large corpus of literature on assessment underscores the importance of assessment as the primary indicator of academic success for students, there is a paucity of literature on the use and value of assessment strategies. CHE presents the view that 'assessment has a critical influence on the quality of teaching and learning and can be used as a powerful point of leverage for change and improvement in education' (CHE 2004b, 5). It is against this 
background of assessment as 'leverage for change', that responses of how four departments viewed assessment as an integral part of the diploma re-curriculation process were explored. Assessment plans for subjects are often inherited and perpetuated by virtue of subject guides in the absence of departmental collaboration and assessment planning at programme level. For example, if the exit-level outcomes of a qualification suggest the kinds of knowledge, competences and qualities that graduates should be able to demonstrate on exiting the qualification, it is incumbent on all lecturers across all levels of learning to collaborate in achieving those outcomes. Developing an assessment strategy at programme level is often overlooked or is simply elusive, in that it does not exist.

\section{THE PURPOSE AND NATURE OF CURRICULUM REVISION}

The impetus for curriculum renewal may be attributed to a range of internal and/or external imperatives. In this instance, re-curriculation came about in response to the South African Qualifications Authority’s (SAQA) revised HEQSF of 2013 (SAQA 2013).

The HEQSF (CHE 2013) has a much greater impact on UoTs with their vocational and professional qualification pathways than on traditional universities that offer mainly general and professional degrees. For example, the national diplomas registered with the SAQA were revised to align with HEQSF (CHE 2013) requirements. In addition, UoTs are tasked with developing new qualifications such as the Advanced Diploma and the Postgraduate Diploma to ensure vertical progression to master's and doctoral levels.

Curriculum revision at this institution had as its focus to effect the kinds of changes that would render vocational-oriented qualifications:

- $\quad$ relevant to current and future educational and professional trends;

- $\quad$ pertinent in developing graduates holistically in terms of knowing, doing and being (Barnett, Parry and Coate 2001) and,

- $\quad$ responsive to the employment sector and society regarding applied competencies and graduate attributes for workplace purposes and public good.

A student-centred approach was adopted that focused on epistemology (knowledge and competencies) and ontology (values, attributes and developing a professional gaze) so that curriculum would 'turn its face both ways' (Barnett 2006, 152) academically and vocationally. To this end, academics engaged in robust, reflective processes of critiquing the existing diploma qualifications offered for several years where merely superficial changes had been made. 


\section{Assessment in higher education}

The discourse of assessment is commonly located in two integrated domains, summative assessment's 'certifying and credentialing role' and formative assessment's 'developmental ends' (Dawson, Bearman, Boud, Hall, Molloy, Bennett and Joughin 2013). Assessment as an integral component of teaching and learning is powerful and dominant in that it: (1) serves as access to promote students from one level to another; (2) provides an indication of what students know (or do not know); (3) serves as an indicator of academic progress, and (4) is the final determinant of academic success. Dawson et al. (2013) assert that since 'assessment is so central to higher education ... it provides a key arena for exploring how academics' decisions can shape the educational environment'. For example, assessment plans are determined by lecturers, departments or institutions where students often do not have a voice regarding assessment pacing, methods or practices. Assessment could be a patent site of hegemony given the kinds of decisions that influence assessment and whether these decisions are based on pedagogical, empirical or rational reasoning. In other words, hegemony is evident in the agency, culture and structure of how assessment occurs at an institution in terms of who dictates or steers assessment practices, what knowledge is assessed, when assessment occurs and how assessment is practised, conducted and measured. Often the academic schedule is dictated by the administrative agenda, or decisions taken by faculty management are irrefutable. Assessment decisions are frequently made and operationalised in such higher education contexts.

In spite of the centrality and importance of assessment in higher education, the overwhelming focus seems to be located within the quality assurance realm of what constitutes good assessment practice. This focus is evident in research and assessment guides and policies, where the virtues of good assessment practices are portrayed as canons for developing good assessments (Morgan and Houghton 2011; Yorke 2003; Airasian and Miranda 2002; Rust 2002; Fowell, Southgate and Bligh 1999). A literature review reveals emergent themes on particular aspects of assessment, including, amongst others:

- $\quad$ formative and summative assessments;

- $\quad$ assessment methods such as portfolios and e-assessments;

- feedback;

- $\quad$ peer and self-assessment;

- $\quad$ integrated assessment; 
- $\quad$ assessment as pedagogy within constructive alignment, and

- $\quad$ deep and surface learning.

(Refer to Trigwell and Prosser 2014; Bayat and Naicker 2012; Crisp 2012; Irwin and Hepplestone 2012; Torrance 2012; Bezuidenhout and Alt 2011; Biggs and Tang 2007; Biggs 2003; Yorke 2003; Rust 2002.)

The literature on assessment strategies that should ideally inform all of the above themes within a programme of study seems to be scant, with 'strategies' often being conflated with 'methods'. Although there is a school of thought that higher education is becoming more managerialist and that it panders to market forces, there is merit in drawing on a management perspective of a strategy and strategic thinking for assessment planning and implementation at programme level. Often lecturers inherit assessment schemes with methods and weightings for the subjects they teach, and pursue these without any rationale why these particular methods and weightings are appropriate. It is argued that within the context of re-curriculation and curriculum development, assessment requires strategic thinking from a programme-wide perspective, that is, developing and managing an assessment strategy for the programme of study that provides context and rationale for decisions made at subject level.

\section{PERSPECTIVES ON ASSESSMENT IN HIGHER EDUCATION}

James $(2014,156)$ alerts us to the pivotal nature of assessment in higher education and the myriad ways in which assessment is defined, approached and applied, 'each of which comes with ontological and epistemological positioning'. James describes three perspectives of how assessment is viewed and practised and suggests that boundaries between these perspectives are permeable and by no means absolute. Elements of one perspective could be evident in another. The three perspectives, according to James (2014), that most often feature in assessment include (1) the technical perspective, (2)humanistic perspective, and (3) interactionist perspective. A brief exposition of each perspective provides insight into how assessment might be viewed in higher education.

James $(2014,156)$ is of the opinion that most discussion and literature on assessment in higher education centres on the technical perspective that foregrounds the 'tick box' criteria of good assessment practice. The technical perspective is concerned with the appropriacy of assessment methods and whether 'matters like fairness, transparency, efficiency ... reliability, validity ... and coherence between assessment processes and learning outcomes' were adhered to (James 2014, 156). The claim that most institutional policies and subsequent departmental assessment plans fall squarely into the technical perspective where emphasis is placed on 
technicist details of assessment principles (James 2014) is validated by this research. For example, a national document on programme development explains assessment requirements for curriculum as having:

appropriate policies and procedures for internal assessment; internal and external moderation; monitoring of student progress; explicitness, validity and reliability of assessment practices; recording of assessment results; settling of disputes; the rigour and security of the assessment system ... (CHE 2004a, 7).

Similarly, the institutional assessment policy, according to the Cape Peninsula University of Technology (CPUT), 'provides academic staff with clear, brief, user-friendly guidelines for fair and valid assessment ... that is appropriate to professionally oriented education' (CPUT 2012, 2). Both the national and institutional guidelines outline specific assessment criteria that present elements of 'good practice' (for example, validity, reliability, fairness, moderation and procedures for handling grievances). By implication, evidence of 'good practice' principles could be interpreted as assessments being fit for purpose when this might not be the case. While there is inherently nothing amiss with providing guidelines to ensure that all assessments meet minimum criteria, it may be argued that assessments are more than tick lists of compliance with institutional standards. The focus of the technicist perspective resides in compliance and seems to evade the issue of whether assessments contribute to epistemological access to knowledge (Morrow 2009) and/or contribute to developing an ontological stance towards self and the profession. Yet, assessments viewed through the lens of the technical perspective 'can be sophisticated' but the critique is that there could be an 'over-reliance on the codification of learning and knowledge through devices like learning outcomes and ... placing too much reliance on generic notions of "good practice”' (James 2014, 157).

The humanistic perspective (James 2014) draws attention to the contradictory expectations of learners and lecturers respectively, where teaching and learning practices set expectations for assessments that might be at odds with what is actually required. In other words, pedagogic practices applied in teaching and learning might be out of kilter with assessment practices. For example, critique and deep learning might characterise learning activities, yet assessment tasks encourage recall and reproduction without further expectations of analysing, comparing, contrasting and substantiating that should typify higher education reasoning and thinking abilities. The converse of this example could also be applicable. While James (2014) advances no explanation for such contradictory practices, the cautionary note is that this could create mistrust between students and lecturers. The divergent expectations of teaching, learning and assessment militate against the principles of constructive alignment and 
occlude developing an understanding of how components and practices of disciplinary pedagogy constitute a holistic whole. The CHE Resource on Assessment of Student Learning (2004b, 3) presents a tenet of constructive alignment for the higher education fraternity, to '[make] explicit the learning outcomes and levels of knowledge, understanding and skills one intends students to achieve and then designing assessment instruments that will effectively test students' attainment of these outcomes'.

Analytic marking schemes that purport to minimise subjectivity and are designed to promote fairness and transparency in assessment are also brought into question for their 'divergent' nature (James 2014, 157). The argument presented by James (2014) is that for students to develop the ability to evaluate and review their own work, a holistic view of the composite output would be required rather than analytical schemes that compartmentalise the whole into what sometimes appear to be discrete tasks. In defence of the humanistic perspective, James suggests that 'many of those teaching in HE have much less individual autonomy ... or find themselves pulled in different directions by assessment purposes other than facilitating student learning'. Often academics are compelled to work within the confines of departmental or faculty assessment practices that might well conflict with their own views of education. It could be argued that the humanistic perspective could arise from diverse interpretations of teaching and learning with different expectations for assessment, or from authoritarian structures at variance with lecturer requirements and expectations. Often lecturers work within the confines of authoritarian decision-making structures and are not at liberty to follow individual or innovative practices.

The interactionist perspective promotes collective thinking and decision making between lecturers and/or lecturers and students, bearing in mind that assessment tasks and results could well be interpreted differently by lecturers and students. Assessment underscores the power relations of the various hierarchical levels in academia that 'can frame [lecturers] actions and ... [where] habitual practices reproduce or contest interests' (James 2014, 158). The interactionist perspective could be viewed as an attempt to minimise an authoritative stance, especially between lecturer and students, while simultaneously clarifying expectations of tasks and assessment criteria. Assessment is a situated, context-dependent, social process and a 'community of judgment' is always relevant (James 2014, 164). The inherent hegemony prevalent in assessments, with lecturers exercising power over what is assessed, how and when assessment occurs, and how marks are allocated, could at times be detrimental to students who have limited recourse to bring about change. The interactionist perspective tends to open channels of communication and allow the student voice to contribute to pedagogy and create opportunities for dialogue in the interests of an improved learning experience. 
In practice, the three perspectives that range from technical aspects of assessment to levels of abstraction, are not mutually exclusive and are largely dependent on the learning environment and the culture in which teaching, learning and assessment occur. Institutional assessment practices are governed by rules, policies and procedures, suggesting that lecturers have limited autonomy to adopt, for example, a more democratic interactionist perspective.

\section{RESPONSES AND DISCUSSION AS SUBMITTED BY DEPARTMENTS}

The re-curriculation of diplomas required departments to respond to questions relating to assessment practices at programme level. (Refer to Table 1 for excerpts of questions and verbatim responses.) The submissions revealed the purpose, interpretation and value placed on assessments at programme level. Four diplomas from four faculties (Applied Sciences, Business, Health and Wellness Sciences, and Informatics and Design) were purposively selected based on their different fields of study to determine how staff viewed assessment as a component of curriculum. The selected diplomas are not attached to professional bodies that may be prescriptive to ensure accreditation of the programme and graduates as professionals in the field of practice. The responses are, therefore, the interpretation of academics in each department, either individual staff members or groups tasked with completing the template. The responses to each question were analysed using content analysis and the discussion focused on the commonalities and/or differences across diploma programmes using James's (2014) perspectives of assessment to frame the discussion.

Table 1: Responses to questions on assessment

\begin{tabular}{|c|c|c|c|}
\hline Diploma A & Diploma B & Diploma C & Diploma D \\
\hline \multicolumn{4}{|c|}{$\begin{array}{l}\text { Question 1: Describe the overall assessment approach applicable to this programme and how this assessment } \\
\text { approach is aligned to the exit-level outcomes of the qualification. }\end{array}$} \\
\hline $\begin{array}{l}\text { Assessment criteria have } \\
\text { been set in accordance } \\
\text { with the exit-level } \\
\text { outcomes of the } \\
\text { programme. } \\
\text { Assessment tools are } \\
\text { weighted in accordance } \\
\text { with the volume of work } \\
\text { assessed and the } \\
\text { cognitive complexity of } \\
\text { the assessment task. } \\
\text { The department adheres } \\
\text { strictly to institutional and } \\
\text { faculty assessment rules } \\
\text { and procedures. } \\
\text { Moderators ensure that } \\
\text { assessment tasks are } \\
\text { fair and that the cognitive } \\
\text { complexity (Bloom's } \\
\text { taxonomy) of the }\end{array}$ & $\begin{array}{l}\text { Includes case studies, } \\
\text { problem-solving } \\
\text { assignments and } \\
\text { strategies, logbooks, } \\
\text { portfolio of learning } \\
\text { materials, projects and } \\
\text { presentations, written and } \\
\text { oral examinations, } \\
\text { authentic practical } \\
\text { exercises and } \\
\text { demonstrations. Some } \\
\text { strategies will be more } \\
\text { suited to assess } \\
\text { foundational competence } \\
\text { while others are more } \\
\text { suited to assess practical } \\
\text { and reflexive competence. } \\
\text { The final integrated } \\
\text { assessment needs to } \\
\text { measure applied } \\
\text { competence [assessing a }\end{array}$ & $\begin{array}{l}\text { Assessment is largely } \\
\text { formative. The } \\
\text { department aligns itself } \\
\text { with all appropriate } \\
\text { policies and procedures } \\
\text { for internal } \\
\text { assessment; internal } \\
\text { and external } \\
\text { moderation; monitoring } \\
\text { of student progress; } \\
\text { explicitness, validity } \\
\text { and reliability of } \\
\text { assessment practices; } \\
\text { recording of } \\
\text { assessment results; } \\
\text { settling of disputes; the } \\
\text { rigour and security of } \\
\text { the assessment } \\
\text { system; RPL; and for } \\
\text { the development of } \\
\text { staff competence in }\end{array}$ & $\begin{array}{l}\text { The assessment approach is } \\
\text { based on the principles of } \\
\text { constructive alignment. The } \\
\text { departmental assessment } \\
\text { focus is on engagement with } \\
\text { and construction of } \\
\text { knowledge. } \\
\text { All assessments subscribe to } \\
\text { institutional guidelines and } \\
\text { include both formative and } \\
\text { summative assessments. All } \\
\text { assessments are moderated } \\
\text { and subscribe to the } \\
\text { appropriate levels. The basic } \\
\text { assessment approach used } \\
\text { in most subjects is as } \\
\text { follows: } \\
\text { - All students write } \\
\text { structured end-of term } \\
\text { tests; }\end{array}$ \\
\hline
\end{tabular}




\begin{tabular}{|c|c|c|c|}
\hline Diploma A & Diploma B & Diploma C & Diploma D \\
\hline $\begin{array}{l}\text { assessment is } \\
\text { commensurate with the } \\
\text { specific outcomes of the } \\
\text { subject, the exit-level } \\
\text { outcomes of the } \\
\text { programme and } \\
\text { corresponding level } \\
\text { descriptors. }\end{array}$ & $\begin{array}{l}\text { case, developing a solution } \\
\text { and applying the solution to } \\
\text { an authentic case - focus } \\
\text { is on problem solving]. }\end{array}$ & $\begin{array}{l}\text { assessment. } \\
\text { Assessment [aligns } \\
\text { with] policy documents, } \\
\text { aligns with the level of } \\
\text { the programme and the } \\
\text { needs of industry. } \\
\text { Assessments are } \\
\text { effective tools for } \\
\text { measuring how } \\
\text { students are coping } \\
\text { and succeeding. }\end{array}$ & $\begin{array}{l}\text { There are practical } \\
\text { projects where they apply } \\
\text { theoretical principles. } \\
\text { - Students will do class } \\
\text { presentations and write } \\
\text { class tests mainly as } \\
\text { formative assessments } \\
\text { during the year. }\end{array}$ \\
\hline
\end{tabular}

Question 2: Describe the main aim(s) or purpose(s) as well as method(s) of assessment for each academic year of study.

- To determine the extent to which learning has taken place.

- To assess whether learning outcomes for the course were achieved.

- To monitor the learning process and development of graduate attributes.

- To reflect on and review where necessary the efficacy of teaching and learning methods.

- To serve as indicators of the extent to which progress has been made towards achieving the level descriptors.

\section{Assessment methods}

Tests, assignments, laboratory reports, oral presentations, project, portfolio

\begin{tabular}{l|l}
$\begin{array}{l}\text { Year 1: To assess } \\
\text { knowledge, to allow } \\
\text { students to understand and } \\
\text { remember the basics of } \\
\text { [content knowledge]. }\end{array}$ & $\begin{array}{l}\text { Largely formative } \\
\text { assessment strategies } \\
\text { are applied though mid } \\
\text { and year-end } \\
\text { moderations are }\end{array}$ \\
$\begin{array}{l}\text { Year 2: } 40-50 \% \\
\text { application ... unless the } \\
\text { subject needs are } \\
\text { structured differently, }\end{array}$ & $\begin{array}{l}\text { The students are } \\
\text { assessed on specific }\end{array}$ \\
assessment criteria.
\end{tabular}

needing more

remembering and

understanding.

Year III: Mostly

application and unknown

resolution of queries.

\begin{abstract}
Assessments are conducted
as part of the learning

process. Formative

assessments are conducted

for learning, to determine the

levels of understanding of

content for both the lecturer

and student. The results of

formative assessments

inform future discussions

and the approach to learning

in terms of providing

adequate academic support.

Summative assessments are

conducted to determine

students' overall

perspectives of units of work.
\end{abstract}

Integrated assessments: The subject content of various

first-year subjects is

integrated into this

assessment.

The knowledge component will be assessed through

knowledge and insight questions in tests. The application component will be assesssed through practical questions in tests, class presentations in groups and practical application projects.

In the first year the focus will be more on knowledge and basic application.

The second and third year will focus on more specialised knowledge and more detailed application.

Assessment methods:

Tests, projects, presentations, research Assignments

Question 3: Will there be an appropriate balance between formative and summative assessments in the programme? Provide details.

Currently, formative assessment is neglected and misunderstood by staff as an assessment
The department follows the continuous assessment system. Students receive ongoing formative
Yes. As attested to by feedback from external examiners and
All summative assesssments are preceded by formative assessments like peer group assessment, etc. The 


\begin{tabular}{|c|c|c|c|}
\hline Diploma A & Diploma B & Diploma C & Diploma D \\
\hline $\begin{array}{l}\text { tool, but also as a } \\
\text { diagnostic tool to assist } \\
\text { in developing a viable } \\
\text { teaching and learning } \\
\text { strategy. Staff } \\
\text { development in respect } \\
\text { of assessment is } \\
\text { essential in the revised } \\
\text { curriculum to ensure that } \\
\text { formative assessment } \\
\text { assume their rightful } \\
\text { place in the new } \\
\text { curriculum. }\end{array}$ & $\begin{array}{l}\text { assessments throughout } \\
\text { the academic year to allow } \\
\text { them to reflect and critically } \\
\text { evaluate their competency } \\
\text { skills. Students will receive } \\
\text { a minimum of four } \\
\text { theoretical or practical } \\
\text { assessments before their } \\
\text { final summative } \\
\text { assessment. }\end{array}$ & $\begin{array}{l}\text { moderators year after } \\
\text { year. }\end{array}$ & $\begin{array}{l}\text { purpose of the formative } \\
\text { assessments are to confirm } \\
\text { and substantiate the } \\
\text { concepts and knowledge } \\
\text { needed before students } \\
\text { embark on the summative } \\
\text { assessments. Formative } \\
\text { assessments in the form of } \\
\text { class tests and work sheets. } \\
\text { These formative } \\
\text { assessments then form the } \\
\text { basis of knowledge and } \\
\text { understanding before } \\
\text { students engage in the } \\
\text { summative assessment. }\end{array}$ \\
\hline \multicolumn{4}{|c|}{$\begin{array}{l}\text { Question 4. Will students be assessed in an integrated and holistic manner in terms of knowledge, skills and } \\
\text { capabilities/attributes in relation to the requirements of complex practice in the field of study? Provide details. }\end{array}$} \\
\hline $\begin{array}{l}\text { No response was } \\
\text { provided. }\end{array}$ & $\begin{array}{l}\text { Assessment is based on } \\
\text { accumulated knowledge } \\
\text { and indicates growth of } \\
\text { knowledge and skills with } \\
\text { various forms of } \\
\text { assessments: formative } \\
\text { and summative } \\
\text { assessments. Integration } \\
\text { of subjects and } \\
\text { assessments will be } \\
\text { encouraged in a holistic } \\
\text { manner. Lecturers will } \\
\text { make use of integrated } \\
\text { assessments aligned to } \\
\text { learning outcomes } \\
\text { appropriate to the SAQA } \\
\text { level descriptors for the } \\
\text { qualification. Graduate } \\
\text { attributes will be embedded } \\
\text { in the subject learning } \\
\text { outcomes which will be } \\
\text { aligned with student } \\
\text { competencies to be } \\
\text { achieved. Students will be } \\
\text { awarded re-assessment } \\
\text { opportunities to achieve } \\
\text { the required competencies. }\end{array}$ & $\begin{array}{l}\text { Yes, because the entire } \\
\text { programme is } \\
\text { structured to simulate } \\
\text { the world of work and } \\
\text { life-long study. }\end{array}$ & $\begin{array}{l}\text { Students will be assessed in } \\
\text { an integrated and holistic } \\
\text { manner in terms of } \\
\text { knowledge, skills and } \\
\text { graduate attributes in relation } \\
\text { to the requirements of } \\
\text { complex practice in the field } \\
\text { of study. The following two } \\
\text { examples are relevant: } \\
\text { In the first year the student } \\
\text { will do a practical market day } \\
\text { that will be assessed by a } \\
\text { content subject, } \\
\text { communication and the use } \\
\text { of computer software. } \\
\text { In the third year the students } \\
\text { will compile a business plan } \\
\text { that will integrate all the } \\
\text { knowledge of all the subjects } \\
\text { learnt from the first year. }\end{array}$ \\
\hline
\end{tabular}

The questions in Table 1 formed part of an institutional template for the recurriculation of diplomas. The responses in Table 1 are verbatim excerpts that reflect departmental perspectives of assessments. For purposes of anonymity, the diplomas were not identified and are referred to as A, B, C and D. Each question is presented below, followed by a discussion of the responses.

\section{Question 1: Describe the overall assessment approach applicable to this programme and how this assessment approach is aligned with the exit level outcomes of the qualification}

For Diploma A, the assessment approach was viewed in terms of aligning subject outcomes 
with exit-level outcomes, assessment criteria and level descriptors, and ensuring that the institutional rules and procedures for assessment were met. For Diploma B the assessment approach was interpreted within the context of demonstrating applied competence. SAQA (2005, i) defines applied competence as ‘a learner's ability to integrate concepts, ideas and actions in authentic, real-life contexts that is expressed as practical, foundational and reflexive competence'. Being a more practice-oriented programme of study, the emphasis was on the application of knowledge in a sequential problem-solving format by means of 'assessing a case, developing a solution and applying the solution to an authentic case'. The assessment approach for Diploma C was presented within the context of the rules and procedures of the institutional policy. Assessments were considered 'tools for measuring how students [were] coping and succeeding' and had to subscribe to the needs of industry and the rules of the institution. The lecturers in Diploma D based their approach on the principles of constructive alignment with their focus being on students' construction of knowledge. This department's understanding and application of formative and summative assessments, constructive alignment, and Bloom's revised taxonomy suggest a developmental approach to improving learning, reasoning and cognition (Airasian and Miranda 2002).

Each department conceived an assessment approach in distinctly different ways, such as alignment of outcomes, cognitive complexity, applied competence and/or constructive alignment. The commonality was that all departments considered compliance with institutional rules and procedures an important part of their assessment approach. These focus areas could be interpreted as the value that departments placed on specifics of assessment. For example, Diploma C considered assessments to be 'tools for measuring' learning, suggesting a technicist perspective of assessments being measuring instruments that should comply with institutional and industry requirements. James's $(2014,157)$ assertion that an 'over-reliance on the codification of learning and knowledge' through different devices seems evident in the centrality of focus areas (alignment of outcomes, level descriptors, applied competence and constructive alignment) to understanding assessment approaches. Airasian and Miranda (2002, 253) are of the view that there is merit in aligning assessments with teaching and learning practices. They contend that 'severe misalignment of assessment, objectives and instruction will likely not lead to high student performance on the assessments'. All the focus areas noted above are pertinent to a comprehensive explanation for an assessment approach, yet discrete aspects were afforded attention. The responses revealed the importance of compliance with institutional and/or national imperatives as rules and procedures were copied verbatim. It could be argued that in the absence of developing an assessment strategy with all its facets, the technicist perspective became the default position. 


\section{Question 2: Describe the main aim(s) or purpose(s) as well as method(s) of assessment for each academic year of study}

The aims of assessment for Diploma A alluded to the purposes of formative and summative assessments and described assessment as being an integral part of teaching and learning. Assessment served as a lens to critique, 'reflect on and review the efficacy of teaching and learning methods'. This suggests a cyclical stance to constructive alignment where assessment provides insight into the kinds of changes that could effect improvement in subsequent teaching, learning and assessment cycles. The assessment methods were sufficiently varied to accommodate different learning styles and the different facets of theory and practice across levels of learning.

Bloom’s revised taxonomy (Airasian and Miranda 2002) served as a basis for explaining the aims and purposes of assessment for Diploma B. In Year 1 of this diploma, the aim was 'to assess knowledge ... to understand and remember the basics'; Year 2 required ' $40 \%-50 \%$ application ... unless the subject needs are structured differently, needing more remembering and understanding' and in Year 3, the focus was mostly on application. Although progressive levels of complexity seemed evident, there was an absence of cognitive challenge beyond application of knowledge. This response reveals an understanding of Bloom's revised taxonomy where the first year of study draws on the lower levels of cognition, 'remembering' and 'understanding', the second year is a continuation of the first year with 'application' included, and the third year focuses mainly on the application of knowledge. The upper levels of Bloom's taxonomy that are meant to assess meta-cognition and higher-order thinking such as, ‘analyse’, ‘evaluate’ and ‘create’ were not included. This interpretation of Bloom's revised taxonomy seems problematic, given that all levels of cognition should feature in all levels of study. For example, at first-year level, students should be challenged to 'analyse' and 'synthesise' with incremental cognitive tasks being scaffolded across the three-year diploma qualification. In addition, the absence of higher-order reasoning and cognition did not align with the level descriptors for higher education (SAQA 2012).

Formative and summative assessments and assessment criteria framed the assessment aims of Diploma $\mathrm{C}$ although no clarification was provided as to how formative and summative assessments were interpreted. No differentiation regarding the aims of assessment was reflected across the three years of study.

The two dominant assessment domains (formative and summative assessments) featured

prominently in Diploma D. The response was comprehensive and showed clarity of understanding as to how formative and summative assessments were used as an integral part of 
the teaching and learning cycle. At second- and third-year levels, the assessment focus was 'on more specialised knowledge and more detailed application'. However, the explanation suggests that theory and practice are separate and are assessed as such, for example, 'the knowledge component will be assessed through knowledge and insight questions ... the application component will be assessed through practical questions'. This trend militates against the integration of different kinds of knowledge, since practical tasks draw on conceptual and procedural knowledge for understanding and implementation.

Each department alluded to formative and summative assessments in the learning process ranging from cryptic statements (Diploma C) to a detailed explanation (Diploma D). While assessment methods varied according to the field of study, clarity on the aims of assessment for each year of study was largely absent or the aims were ill-defined. It could be argued that if there is a lack of clarity on the aims and purposes of assessment at programme level, this could have implications for assessment practices at subject level if lecturers do not have a clear understanding of how assessment is applied and integrated into the cycle of teaching, learning and assessment. The separation of theory and application of knowledge seems problematic, especially for vocational education. The responses aligned with information in the institutional policy suggesting limited reflection on the importance of how assessment contributes to the acquisition of knowledge, competences and values for vocational education. The technicist perspective was prevalent in compliance with institutional commitments without presenting a broader contextualisation of how the question was interpreted within each field of study.

\section{Question 3: Will there be an appropriate balance between formative and summative assessments in the programme? Provide details}

Formative assessments formed part of assessment practices for each diploma, to a lesser or more noteworthy degree, as follows:

- $\quad$ The comment that formative assessment for Diploma A was 'neglected and misunderstood by staff' called for staff development in this domain.

- Diploma B explained the relationship and function of formative and summative assessments within the context of continuous assessment.

- Diploma C drew on feedback from moderators to confirm the relationship between formative and summative assessments without providing any clarification or explanation.

- Diploma D provided a clear understanding of lecturers' interpretation of the relationship between formative and summative assessments as part of assessment practice. 
The responses to this question suggest that the clarification (or lack thereof) of assessment terms has implications for teaching, learning and assessment. If educational jargon is not clarified at programme level, subject lecturers will be left to decipher for themselves what practices to implement. This does not imply that there is a direct consequence between understanding terminology and effective implementation in practice, but it does imply that if opportunities to discuss all aspects of assessment are not created and valued at programme level, uniform practices to support all students might be elusive and could negatively influence their academic performance. The need for professional development seems evident in three departments, given the perceived inability to provide comprehensive responses.

\section{Question 4. Will students be assessed in an integrated and holistic manner in terms of knowledge, skills and capabilities/attributes in relation to the requirements of complex practice in the field of study? Provide details}

Diploma A did not respond to this question. The interpretation of this question for Diploma B included references to formative and summative assessments, the integration of subjects in a holistic manner, and that the assessment of graduate attributes would be embedded in subject learning. The response did not allude to how assessments related to the particular field of study. In contrast, for Diploma C, 'the entire programme [was] structured to simulate the world of work and life-long study’ with no further explication of this statement. No reference was made to any other aspects of assessments as required of the question. The response from Diploma D took the form of an explanation of an integrated assessment where knowledge and competences of three subjects were integrated for an authentic assessment task that mirrored workplace practices.

The responses for all four diploma programmes provided limited information on how knowledge, skills and attributes would be assessed holistically within the context of the field of study. The brevity of information could suggest limited understanding by departments of what was required or that assumptions were made that reviewers for accreditation of the qualifications would understand the context and fill in the omissions.

\section{Discussion}

The responses to each of the questions by the different departments revealed different understandings of assessment purposes and practices, starting with different terms, that is, 'tools' and 'strategies' for assessment methods. Although assessments were varied, no rationale was provided for the selection of assessment methods. Attempts were made to demonstrate 
understanding of assessment but the focus seemed to be on technicist thinking and compliance with institutional rules. The importance of accumulative knowledge building across the levels of learning was diminished. Comprehension and analysis seemed to be the threshold at which cognition was pitched, entrenching declarative knowledge without due attention paid to the application of functional knowledge and higher-order thinking. The limited information provided suggests that not all departments grappled adequately with the construct of assessment as a profound component of pedagogy that has long-term consequences for students. The responses suggest a narrow view on specific aspects, without paying due attention to other equally pertinent points relevant to each question.

The evidence provided, it might be argued, suggests that a compelling argument could be made for departments to engage in debate on the role of assessment at programme level. Common understandings and a collaborative approach to assessment could encourage lecturers to work towards achieving common departmental goals regarding knowledge, competences and attributes. The ramifications of clarifying understanding and improved collaboration could contribute to higher-order thinking and deep learning that should translate into improved student academic performance. In other words, the importance of developing an assessment strategy is paramount to improving knowledge about and practices of assessment. For academics, learning and reflection reside in the process of developing a strategy and the product should represent collaborative input that is scaffolded to subject level. As Mutch $(2002,166)$ succinctly states, 'the concern is more with "strategising” as a process than of a strategy as a product'. Furthermore, 'assumptions about assessment need to be formalised and articulated, so that they can be debated amongst a larger staff constituency’ (Mutch 2002, 164). This could encourage innovation and creativity among staff and obviate possibilities of authoritarianism.

\section{PROPOSAL FOR ASSESSMENT STRATEGY}

While no attempt is made to incorporate managerial principles into education, there is acknowledgement that strategic thinking provides direction and purpose (Mutch 2002). Drawing on Naylor (2004) and Gimbert (2011), the following points hold merit for developing an assessment strategy at programme level:

- A strategy requires reflection and reasoning to provide an overview of the objectives and practices adopted by the department.

- A strategy requires collaborative efforts by all staff in a department to achieve strategic goals. 
- A strategy allows for extroverted (looking outwards to the social and work environment) and inward-looking perspectives (to programme and institutional guidelines) as they are all inter-related.

- A strategy provides a long-term perspective of assessment for the programme of study, for review and revision at various intervals.

Naylor $(2004,248)$ suggests a four-stage process of developing a strategy that could be adapted for higher education: (1) analysis, (2) selection, (3) implementation, and (4) control and evaluation. Refer to Table 2.

Table 2: Developing an assessment strategy for a programme of study

\begin{tabular}{|c|c|c|c|}
\hline $\begin{array}{l}\text { Analysis at } \\
\text { programme level } \\
\text { (Macro-level) }\end{array}$ & $\begin{array}{l}\text { Selection at subject } \\
\text { level } \\
\text { (Meso-level) }\end{array}$ & $\begin{array}{l}\text { Implementation at } \\
\text { assessment level } \\
\text { (Micro-level) }\end{array}$ & $\begin{array}{l}\text { Control and Evaluation } \\
\text { (Programme, Subject } \\
\text { and Assessment levels) } \\
\text { (Macro-, Meso-, and } \\
\text { Micro-levels) }\end{array}$ \\
\hline $\begin{array}{l}\text { - Purpose and } \\
\text { rationale of } \\
\text { qualification } \\
\text { - Exit-level outcomes } \\
\text { - Graduate outcomes } \\
\text { IAttributes } \\
\text { - Disciplinary } \\
\text { literacies } \\
\text { - Knowledge and } \\
\text { knower structures } \\
\text { - Teaching and } \\
\text { learning activities } \\
\text { - Curriculum } \\
\text { coherence for types } \\
\text { and integrated } \\
\text { assessment } \\
\text { - Core areas of } \\
\text { knowledge, } \\
\text { competences and } \\
\text { values of the } \\
\text { programme of study } \\
\text { - Purposes and types } \\
\text { of formative and } \\
\text { summative } \\
\text { assessments } \\
\text { - Staff development }\end{array}$ & $\begin{array}{l}\text { - Assessment methods, } \\
\text { question types and } \\
\text { weightings } \\
\text { - Pacing and sequencing } \\
\text { of assessments } \\
\text { - Pacing and sequencing } \\
\text { of content for integrated } \\
\text { assessments } \\
\text { - Level descriptors for } \\
\text { each subject and year } \\
\text { of study } \\
\text { - Opportunities for } \\
\text { innovation and change } \\
\text { relevant to 'analysis' } \\
\text { factors. } \\
\text { - Work-integrated } \\
\text { learning }\end{array}$ & $\begin{array}{l}\text { - Apply good practice } \\
\text { principles of validity, } \\
\text { reliability, } \\
\text { authenticity and } \\
\text { fairness } \\
\text { - Apply decisions } \\
\text { made during the } \\
\text { 'Analysis' and } \\
\text { 'Selection' phase to } \\
\text { all subjects in the } \\
\text { programme } \\
\text { - Develop rubrics for } \\
\text { assignments } \\
\text { - Appropriate } \\
\text { feedback } \\
\text { - Opportunities for } \\
\text { innovation and } \\
\text { change relevant to } \\
\text { 'Analysis' factors. }\end{array}$ & $\begin{array}{l}\text { - Moderation } \\
\text { - Monitoring } \\
\text { effectiveness of } \\
\text { selection and } \\
\text { implementation } \\
\text { Reflection and review of } \\
\text { assessments to: } \\
\text { - encourage deep } \\
\text { learning } \\
\text { - achieve the exit-level } \\
\text { outcomes and graduate } \\
\text { attributes } \\
\text { - determine amendments } \\
\text { and improvement } \\
\text { - evaluate the efficacy of } \\
\text { constructive alignment } \\
\text { (i.e. evaluate teaching } \\
\text { methods, learning } \\
\text { activities, assessment } \\
\text { criteria and assessment } \\
\text { methods } \\
\text { - evaluate whether good- } \\
\text { practice principles were } \\
\text { achieved. }\end{array}$ \\
\hline
\end{tabular}

The selection of components for each of the four stages is contingent on the discussion and decisions taken in the preceding stage. The findings of this research with the often disparate and incomplete responses suggest that a strategic approach could prove useful in assisting departments to: 
- $\quad$ align assessment strategies, policies, procedures and practices;

- $\quad$ clarify thinking about the multiple purposes of assessment for the field of study;

- $\quad$ align assessment with the theories of and approaches to learning, and locating assessment within these theories and approaches;

- $\quad$ adopt strategies that can be justified as a product of critical reflection;

- $\quad$ diminish fragmentation and develop a coherent structure for staff and students;

- $\quad$ develop a strategy that forms part of the learning and reflection for future improvement (Mutch 2002, 168);

- 'bring into view (and keep in view) the circumstances that give us a current set of practices and which current practices reproduce, refine or challenge' (James 2014, 162);

- $\quad$ promote thinking and practices for educational advantage within a super-complex world (Barnett 2000).

Although a strategic approach could direct thinking and reflection, it is not presented as a panacea for improved assessment practices. If the institutional environment is not conducive to change or a dominant culture of authoritarianism is prevalent, lecturers could well adopt the default position of prior assessment practices. Similarly, given that the process for developing strategies for assessment is dynamic and iterative, lecturers should be open to shifting thinking and develop a learning cultures perspective to embrace new learning challenges. James (2014, 164) presents a succinct summation of learning to effect change:

A learning cultures perspective is geared to exploring and articulating the social practices through which people learn, and this must include a careful examination of what concepts and notions of learning, knowledge, curriculum and judgement are in play in a given setting. One reason this may be a useful thing to do is the highly practical one of staff becoming more accustomed to articulating what they find most productive in pedagogic arrangements, if only to defend or negotiate more effectively when those come under pressure to change.

\section{CONCLUSION}

Assessment is the only means by which students are judged competent and eligible to be promoted from one level to another. As such, it is a powerful role player in the realm of teaching and learning. As noted by Brown (in Rust 2002, 145):

Assessment defines what students regard as important, how they spend their time and how they come to see themselves as students and then as graduates ... If you want to change student learning then change the methods of assessment. 
Curriculum development provides an opportunity to reflect on and evaluate past assessment practices, as well as exploring innovative methods to engender student-centred learning and construction of knowledge using different guises and gazes. Assessment, as an integral part of the teaching and learning process, should gain its rightful place and recognition as a powerful tool in cognition and learning. This may only be achieved if the assessment strategy is developed in such a way that it 'fosters a meaningful bridge' between the myriad components that constitute teaching, learning and assessment. The promise of adopting a strategic approach to assessment is that implementation 'must be as a result of conscious decisions based on informed choice’ (Mutch 2002, 166).

\section{REFERENCES}

Airasian, P. W. and H. Miranda. 2002. The role of assessment in the revised taxonomy. Theory into Practice 41(4): 249-264.

Barnett, M. 2006. Vocational knowledge and vocational pedagogy. In Knowledge, curriculum and qualifications for South African further education, ed. M. Young and J. Gamble, 143-157. Cape Town: HSRC Press.

Barnett, R. 2000. Supercomplexity and the curriculum. Studies in Higher Education 25(3): 255-265.

Barnett, R., G. Parry and K. Coate. 2001. Conceptualising curriculum change. Teaching in Higher Education 6(4): 435-449.

Bayat, A. and V. Naicker. 2012. Towards a learner-centred approach: Interactive online peer assessment. South African Journal of Higher Education 26(5): 891-907.

Bezuidenhout, M. J. and H. Alt. 2011. ‘Assessment drives learning': Do assessments promote high level cognitive processing? South African Journal of Higher Education 25(6): 1062-1076.

Biggs, J. 2003. Aligning teaching and assessment to curriculum objectives. York: Learning Teaching and Support Network Generic Centre.

Biggs, J. and C. Tang. 2007. Teaching for quality learning at university: What the student does. Maidenhead: Open University Press; McGraw-Hill Education.

Cape Peninsula University of Technology. 2012. Policy on assessment in professionally-oriented programmes. Bellville: CPUT.

CHE see Council on Higher Education.

CPUT see Cape Peninsula University of Technology.

Council on Higher Education. 2004a. Higher Education Quality Council criteria for programme accreditation. Pretoria: CHE.

Council on Higher Education. 2004b. Teaching and Learning Resource No.5: Assessment of Student Learning. Pretoria: Council on Higher Education.

Council on Higher Education. 2007. Higher education qualifications framework. Pretoria: CHE.

Council on Higher Education. 2013. Higher education qualifications sub-framework. Pretoria: CHE.

Crisp, G. T. 2012. Integrative assessment: Reframing assessment practice for current and future learning. Assessment \& Evaluation in Higher Education 37(1): 33-43.

Dawson, P., M. Bearman, D. J. Boud, M. Hall, E. K. Molloy, S. Bennett and G. Joughin. 2013. Assessment might dictate the curriculum, but what dictates assessment? Teaching \& Learning Inquiry: The ISSOTL Journal 1(1): 107-111.

Fowell, S. L., L. J. Southgate and J. G. Bligh. 1999. Evaluating assessment: The missing link? Medical 
Education 33(4): 276-281.

Gimbert, X. 2011. Think strategically. Basingstoke: Palgrave Macmillan.

Irwin, B. and S. Hepplestone. 2012. Examining increased flexibility in assessment formats. Assessment \& Evaluation in Higher Education 37(7): 773-785.

James, D. 2014. Investigating the curriculum through assessment practice in higher education: The value of a 'learning cultures' approach. Higher Education 67(2): 155-169.

Knight, P. 2000. The value of a programme-wide approach to assessment. Assessment \& Evaluation in Higher Education 25(3): 237-251.

Knight, P. 2001. Complexity and curriculum: A process approach to curriculum-making. Teaching in Higher Education 6(3): 369-381.

Morgan, H. and A-M. Houghton. 2011. Inclusive curriculum design in higher education: Considerations for effective practice across and within subject areas. York: Higher Education Academy.

Morrow, W. E. 2009. Bounds of democracy: Epistemological access in higher education. Cape Town: HSRC Press.

Mutch, A. 2002. Thinking strategically about assessment. Assessment \& Evaluation in Higher Education 27(2): 163-174.

Naylor, J. 2004. Management. 2nd ed. Harlow: Pearson Education.

Rust, C. 2002. The impact of assessment on student learning. Active Learning in Higher Education 3(2): 145-158.

SAQA see South African Qualifications Authority.

South African Qualifications Authority. 2005. Guidelines for integrated assessment. Pretoria: SAQA.

South African Qualifications Authority. 2012. Level descriptors for the South African National Qualifications Framework. Pretoria: SAQA.

Torrance, H. 2012. Formative assessment at the crossroads: Conformative, deformative and transformative assessment. Oxford Review of Education 38(3): 323-342.

Trigwell, K. and M. Prosser. 2014. Qualitative variation in constructive alignment in curriculum design. Higher Education 67(2): 141-154.

Yorke, M. 2003. Formative assessment in higher education: Moves towards theory and the enhancement of pedagogic practice. Higher Education 45(4): 477-501. 